\title{
Comparison of Changes in PPV Using a Tidal Volume Challenge with a Passive Leg Raising Test to Predict Fluid Responsiveness in Patients Ventilated Using Low Tidal Volume
}

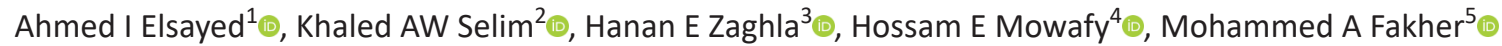

\begin{abstract}
Background: Tidal volume challenge pulse pressure variation (TVC-PPV) is considered one of the recent reliable dynamic indices of fluid responsiveness (FR); also, passive leg raising (PLR)-induced changes in cardiac output (CO) detected by echocardiography are considered a reliable reversible self-fluid challenge test; many patients share eligibility for both tests.

Objectives: The study aimed to compare the sensitivity and specificity of both tests for the prediction of FR in mechanically ventilated patients with hemodynamic instability.

Methods: We studied 46 patients. Hemodynamic parameters including PPV and CO (detected by velocity time integral (VTI) using echocardiography) recorded at tidal volume (VT) of $6 \mathrm{~mL} / \mathrm{kg} /$ ideal body weight (IBW) in semi-recumbent position then recorded again after one-minute increase in TV from 6 to $8 \mathrm{~mL} / \mathrm{kg} / \mathrm{IBW}$ then recorded with PLR at TV of $6 \mathrm{~mL} / \mathrm{kg} / \mathrm{IBW}$ and finally with actual volume expansion in semi-recumbent position by $4 \mathrm{ml} / \mathrm{kg}$ bolus of crystalloid solution to define actual responders with increase of cardiac output of $15 \%$ or more. Results: Sixteen patients were responders, and thirty patients were nonresponders; responders had significant increase in PPV with TVC 6 to $8 \mathrm{ml} / \mathrm{kg} / \mathrm{IBW}$ with best cutoff value of 3.5 with a sensitivity of $93.8 \%$ and a specificity of $93.9 \%$. PLR test-induced changes in CO had a sensitivity of $93.9 \%$ and a specificity of $86.7 \%$ with statistically best cutoff value of $6.5 \%$ increase in CO, but sensitivity was $75 \%$ at cutoff value of $10 \%$ increase in CO. Other parameters like PPV, PPV changes with PLR test, and PPV changes with fluid expansion were less sensitive indicators.

Conclusion: $F R$ in patients with hemodynamic instability and mechanically ventilated with low tidal volume strategy can be efficiently predicted when PPV increases more than 3.5 with tidal volume challenge and when PLR induces $6.5 \%$ increase in CO monitored through VTI method by Doppler echocardiography, and both tests are equally reliable.

Keywords: Fluid responsiveness, Passive leg raising, Pulse pressure variation, Tidal volume challenge.

Indian Journal of Critical Care Medicine (2021): 10.5005/jp-journals-10071-23875
\end{abstract}

\section{INTRODUCTION}

Volume expansion is a cornerstone treatment of acute circulatory failure like during the early hours in patients with septic shock, but it can be a cause of therapeutic dilemma because fluid overload can lead to acute kidney injury, prolongation of mechanical ventilation, acute respiratory distress syndrome (ARDS), and higher mortality rates. ${ }^{1-4}$ Predicting fluid responsiveness with a reliable, easy, and rapid way is essential to know when to start and when to stop fluid therapy especially as patients may react differently to VE. ${ }^{5}$ Static hemodynamic parameters like inferior vena cava diameter and central venous pressure are unreliable and cannot predict FR precisely; contrarily, dynamic parameters that depend on cyclic changes in cardiac preload caused by mechanical ventilation, leading to variation of stroke volume (SV) or pulse pressure (PPV), have proven to be reliable when predicting FR in hemodynamically unstable patients. ${ }^{6,7}$

PPV is a common dynamic parameter that can predict FR reliably and can be recorded through most of recent bedside monitors easily using arterial lines; also, it does not need $\mathrm{CO}$ monitoring or any other maneuvers to be done..$^{8,9}$ One of its important drawbacks, being inaccurate when using low tidal volume strategy, is considered a common ventilation strategy among critically ill patients. ${ }^{10}$ Some papers have recently shown that using the changes in PPV with tidal volume challenge (TVC-PPV) can overcome these limitations and improve PPV accuracy with low tidal volume strategy. Tidal volume challenge was done by elevating tidal volume from

\begin{abstract}
${ }^{1}$ Department of Critical Care, Kasralainy Medical School of Medicine, Giza, Egypt

${ }^{2}$ Department of Critical Care, Faculty of Medicine, Cairo University, Cairo, Egypt

${ }^{3-5}$ Critical Care Medicine Department, Cairo University, Cairo, Egypt

Corresponding Author: Ahmed I Elsayed, Department of Critical Care, Kasralainy Medical School of Medicine, Giza, Egypt, Phone: +20 01065115685, e-mail: Dr.ahmednet96@gmail.com

How to cite this article: Elsayed Al, Selim KAW, Zaghla HE, Mowafy HE, Fakher MA. Comparison of Changes in PPV Using a Tidal Volume Challenge with a Passive Leg Raising Test to Predict Fluid Responsiveness in Patients Ventilated Using Low Tidal Volume. Indian J Crit Care Med 2021;25(6):685-690.
\end{abstract}

Ethics approval and consent for participation: Applied.

Source of support: Nil

Conflict of interest: None

specificity $6 \mathrm{ml} / \mathrm{kg} \mathrm{IBW}$ to $8 \mathrm{ml} / \mathrm{kg} \mathrm{IBW}$ for only 60 seconds and noticing the change in PPV ( $\triangle$ PPV6-8). ${ }^{11}$

PLR test is considered a reversible "preload challenge" of around $300 \mathrm{ml}$ of blood that can be repeated frequently when required without infusing any fluids. ${ }^{12}$ It is reliable during low tidal volume ventilation with estimated sensitivity of $85 \%$ and of $91 \%$ 
according to many studies ${ }^{13}$ other reason behind. The popularity of PLR is being reliable in patients with arrhythmias or spontaneous breathing. $^{14}$

Direct measurement of $\mathrm{CO}$ is essential when performing PLR to assess its effects. The mean cutoff value that achieved best sensitivity and specificity was an increase in CO of $10 \%$ or more during PLR. ${ }^{14}$ Multiple minimally invasive or noninvasive techniques have been used to evaluate PLR-induced changes in CO. ${ }^{9,15-17}$ However, many patients share eligibility for these two common tests that can reliably predict FR in hemodynamically unstable patients on low tidal volume ventilation strategy, and no study has made a direct comparison between them.

\section{Methods}

\section{Study Design}

Prospective study.

\section{Study Setting}

The study was held at Cairo University hospitals, critical care department, between November 2018 and November 2019.

\section{Study Population}

After purposeful sampling technique was used and local ethics committee approval, 55 patients were included with obtaining written informed consent.

\section{Inclusion Criteria}

Adult patients with hemodynamic instability who are intubated and mechanically ventilated with volume assist-control ventilation (ACV) and using low tidal volume strategy $(6 \mathrm{ml} / \mathrm{kg} / \mathrm{lBW})$. All patients were fully sedated and not on vasopressors or receiving stable doses of vasopressors. ${ }^{18}$

\section{Exclusion Criteria}

Contraindications for PPV (spontaneous breathing, cardiac arrhythmias, open chest, right-side heart failure, pulmonary or intra-abdominal hypertension, HR/RR $<3.6$ ) or contraindications for PLR (head trauma, venous compression stockings).

\section{Measurements}

PPV measurements were obtained by using the Mindray monitors (iMEC10) through radial arterial lines connected. Cardiac output was obtained through VTI assessment by using echocardiography machine through Doppler study which was performed by the same operator using a standard transthoracic probe (P4-2, Siemens Medical System, Malvern, PA, USA) and a dedicated unit (Acuson ×300, Siemens Medical System, Malvern, PA, USA). ${ }^{19}$

TVC was done by temporarily elevating tidal volume from $6 \mathrm{ml} / \mathrm{kg}$ IBW to $8 \mathrm{ml} / \mathrm{kg}$ IBW for 60 seconds. PLR test was done by lifting both lower limbs while straight for $45^{\circ}$ with the trunk lowered in the supine position for 90 seconds. All other ventilator parameters like respiratory rate and PEEP were unchanged during the study.

\section{CO Measurement by Transthoracic Echocardiography}

Stroke volume was obtained through velocity time integral (VTI) of left ventricular outflow tract (LVOT) blood flow using Doppler tracing envelopes. The product of LVOT area and VTI equals the stroke volume. CO can be obtained by multiplying the SV by heart rate. In our study, CO was obtained from the average of three envelopes of LVOT Doppler tracings in each step.

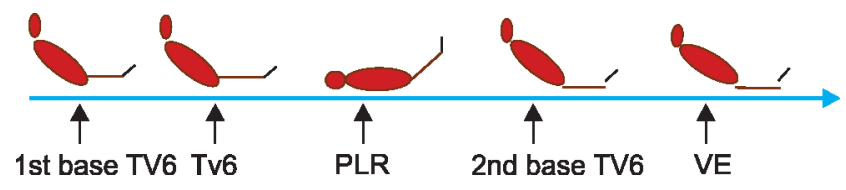

Fig 1: Study protocol and codes.

\section{Study Protocol}

We recorded five sets of hemodynamic measurements (HR, MAP, PPV, CO, and RR) at different times as shown in protocol sequence (Fig. 1).

- First group of measurements was obtained in semi-recumbent position $\left(45^{\circ}\right)$ on tidal volume $6 \mathrm{ml} / \mathrm{kg} / \mathrm{IBW}$ (designated as first base).

- Then, TVC was done while the patient is totally sedated, and a second group of measurements was recorded (TVC).

- Then, PLR test was done, and a third group of measurements was obtained at the end (PLR).

- The patient was then got back to the semi-recumbent position, and a fourth set of measurements was recorded again after 90 seconds (designated as base 2, pre-VE).

- Finally, the same measurements were obtained after VE with $4 \mathrm{ml} / \mathrm{kg}$ crystalloid solution (ringer lactate or normal saline $0.9 \%$ ) over 15 minutes (designated as after VE).

Patients were considered responders if cardiac output was increased with volume expansion by more than $15 \%$ (from baseline 2 pre-VE). Test was canceled when sudden change in HR occurred, pulmonary edema and severe decrease in blood pressure.

\section{Data Management and Statistical Analysis}

Multiple PPV and CO readings were coded as shown in Figure 1. Data were coded and entered using the Statistical Package for the Social Sciences (SPSS) version 25 (IBM Corp., Armonk, NY, USA). Comparisons between quantitative variables were done using the nonparametric Mann-Whitney test. ${ }^{20}$ For comparing categorical data, chi-square $(\times 2)$ test was performed. ${ }^{21}$

\section{Results \\ Study Population}

Eligibility process is shown in Flowchart 1. Sixteen patients were responders (Rs), and thirty were nonresponders (NRs). The general characteristics of the responders and nonresponders are reported in Table 1, and none of them was significant. Also, majority of studied patients (40) had septic shock but shock type did not differ significantly between both groups.

Effects of TVC test, PLR, and VE on hemodynamic variables in $\mathrm{R}$ and NR are shown in Table 2. Responders had higher PPV0 (at baseline $6 \mathrm{ml}$ TV) with mean value of 16.81 with SD of 7.3 with significant $p$ value of $(<0.001)$ with best cutoff value of 10.5 and area under ROC of 0.78 with a sensitivity and specificity of $87 \%$ and $83 \%$, respectively.

Responders had significant increase in PPV with tidal volume challenge $8 \mathrm{ml}$ (delta PPV1) with best cutoff value of 3.5 with area under the curve of 0.95 with sensitivity of $93.8 \%$ and specificity of 93.9\%. In our study, we had one case with false-negative test and two cases with false positive test. Also, PPV at $8 \mathrm{ml} / \mathrm{kg} / \mathrm{lBW}$ predicted responders with $p$ value less than 0.001 (Table 3). At TVC, mean $C_{\text {stat }}$ increased to $29.06 \pm 3.71 \mathrm{ml} / \mathrm{cm} \mathrm{H}_{2} \mathrm{O}$ in responders (compared to $24.38 \pm 3.76 \mathrm{ml} / \mathrm{cm} \mathrm{H} 2 \mathrm{O}$ at base one) and $34.73 \pm 6.94 \mathrm{ml} / \mathrm{cm} \mathrm{H}_{2} \mathrm{O}$ 
Flowchart 1: Eligibility Process for study population.

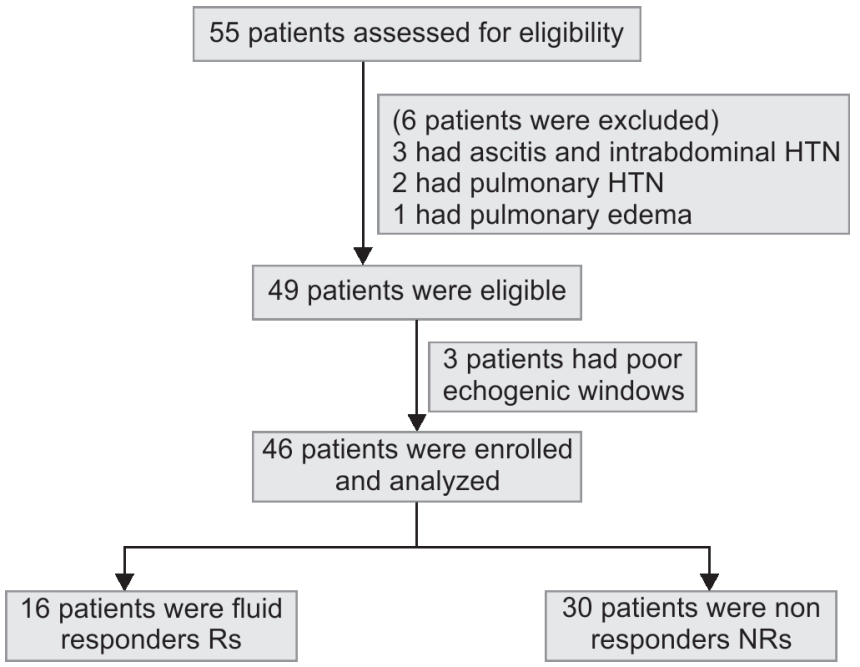

in nonresponders (compared to $29.87 \pm 6.95 \mathrm{ml} / \mathrm{cm} \mathrm{H} 2 \mathrm{O}$ at base one) (Table 3).

During PLR test, there was a significant decrease in PPV (delta PPV2) in responders with $87.5 \%$ sensitivity and $80 \%$ specificity (best cutoff value 2.5 and area under the curve of 0.877 ); the mean $\mathrm{CO}$ increased significantly with PLR test in responders $0.18 \pm 0.10$ compared to $-0.01 \pm 0.1$ in nonresponders; this was highly significant with statistically best cutoff value of $6.5 \%$ with 0.94 area under the curve, $93.8 \%$ sensitivity, and $86.7 \%$ specificity, but sensitivity was $75 \%$ with specificity of $86 \%$ with cutoff value of $10 \%$ (0.099) increase in CO (Table 4).

PPV pre-VE mean value was 15.06 with SD of 6.87 , which was significant but did not affect the number of responders and nonresponders; also, CO pre-VE mean value was 4.58 with SD of 1.16 with no significance, which means that the PLR test and tidal volume challenge effects on hemodynamics were rapidly reversible after the end of this test. Changes of PPV test with volume expansion with $500 \mathrm{ml}$ crystalloids (delta PPV 3) showed significant decrease in PPV

Table 1: Patient characteristics in responders and nonresponders

\begin{tabular}{|c|c|c|c|c|}
\hline Patient characteristics & & Responders $(n=16)$ & Nonresponders $(n=30)$ & $p$-value \\
\hline \multirow[t]{2}{*}{ Gender freq. (\%) } & Male & $8(50)$ & $20(66.7)$ & 0.27 \\
\hline & Female & $8(50)$ & $10(33.3)$ & \\
\hline Age (years) & Mean \pm SD & $60.25 \pm 13.82$ & $59.97 \pm 12.98$ & 0.954 \\
\hline Ideal body weight (kg) & Mean \pm SD & $70.5 \pm 7.98$ & $66.33 \pm 8.57$ & 0.13 \\
\hline $\mathrm{BMI}\left(\mathrm{kg} / \mathrm{m}^{2}\right)$ & Mean \pm SD & $30.31 \pm 3.24$ & $29.13 \pm 3.79$ & 0.287 \\
\hline APACHE II score & Mean \pm SD & $19.75 \pm 6.88$ & $19.9 \pm 4.99$ & 0.711 \\
\hline \multirow[t]{4}{*}{ Shock type } & Cardiogenic & $1(6.3)$ & $0(0)$ & 0.056 \\
\hline & Septic & $13(81.3)$ & $27(90)$ & \\
\hline & Septic and cardiogenic & $0(0)$ & $3(10)$ & \\
\hline & Septic and hypovolemic & $2(12.5)$ & $0(0)$ & \\
\hline
\end{tabular}

Table 2: Hemodynamic variables and lung compliance between responders and nonresponders

\begin{tabular}{|c|c|c|c|c|c|c|}
\hline Parameters & Group & Base 1 & TVC & $P L R$ & Base 2 pre-VE & VE $500 \mathrm{ml}$ \\
\hline \multirow[t]{2}{*}{ HR (bpm) } & $\mathrm{R}$ & $101 \pm 14$ & $100 \pm 14$ & $102 \pm 14$ & $104 \pm 14$ & $98 \pm 13$ \\
\hline & NR & $109 \pm 15$ & $107 \pm 14$ & $109 \pm 15$ & $110 \pm 15$ & $106 \pm 14$ \\
\hline \multirow[t]{2}{*}{$\mathrm{SAP}(\mathrm{mm} \mathrm{Hg})$} & $\mathrm{R}$ & $95 \pm 10$ & $90 \pm 10$ & $97 \pm 11$ & $97 \pm 11$ & $104.5 \pm 11$ \\
\hline & NR & $97 \pm 12$ & $93 \pm 12$ & $99 \pm 12$ & $97 \pm 12$ & $102 \pm 13$ \\
\hline \multirow[t]{2}{*}{ MAP $(\mathrm{mm} \mathrm{Hg})$} & $\mathrm{R}$ & $70 \pm 6$ & $67 \pm 5$ & $72 \pm 5.5$ & $71 \pm 6$ & $77.5 \pm 5$ \\
\hline & NR & $68 \pm 6.5$ & $65 \pm 6$ & $70 \pm 6.5$ & $68.5 \pm 6.5$ & $72 \pm 6.5$ \\
\hline \multirow[t]{2}{*}{$\mathrm{DAP}(\mathrm{mm} \mathrm{Hg})$} & $\mathrm{R}$ & $58 \pm 6$ & $56 \pm 6$ & $60 \pm 5.6$ & $60 \pm 5.7$ & $64 \pm 5.5$ \\
\hline & NR & $54 \pm 6$ & $51.5 \pm 6$ & $55 \pm 6.5$ & $54 \pm 6.5$ & $57 \pm 6.5$ \\
\hline \multirow[t]{2}{*}{ PPV (\%) } & $\mathrm{R}$ & $16.8 \pm 7.2$ & $22.5 \pm 8.8$ & $12.3 \pm 7.3$ & $15 \pm 6.8$ & $8 \pm 1.74$ \\
\hline & NR & $10.2 \pm 5$ & $12.2 \pm 6$ & $8 \pm 4$ & $9 \pm 4.5$ & $7 \pm 4$ \\
\hline \multirow[t]{2}{*}{$\mathrm{CO}(\mathrm{VTI})(\mathrm{ml} / \mathrm{m})$} & $\mathrm{R}$ & $4.5 \pm 1.20$ & $3.92 \pm 1.24$ & $5.37 \pm 1.21$ & $4.58 \pm 1.15$ & $5.54 \pm 1.17$ \\
\hline & NR & $5.08 \pm 0.79$ & $4.53 \pm 0.81$ & $5.0 \pm 0.78$ & $5.0 \pm 0.78$ & $5.08 \pm 0.80$ \\
\hline \multirow[t]{2}{*}{ Compliance $\left(\mathrm{ml} / \mathrm{cm} \mathrm{H}_{2} \mathrm{O}\right)$} & $\mathrm{R}$ & $24.38 \pm 3.76$ & $29.06 \pm 3.71$ & - & - & - \\
\hline & NR & $29.87 \pm 6.95$ & $34.73 \pm 6.94$ & - & - & - \\
\hline
\end{tabular}

R: responders; NR: nonresponders; HR: heart rate; SAP: systolic arterial pressure; MAP: mean arterial pressure; DAP: diastolic arterial pressure; PPV: pulse pressure variation; CO: cardiac output; TVC: tidal volume challenge; PLR: passive leg raising; VE: volume expansion 
Tidal Volume Challenge versus Passive Leg Raising

Table 3: Changes of hemodynamic variables throughout the study between responders and nonresponders

\begin{tabular}{|c|c|c|c|}
\hline & Responders $(n=16)$ & Nonresponders $(n=30)$ & \\
\hline PPV and CO changes & Mean $\pm S D$ & Mean $\pm S D$ & pvalue \\
\hline PPV base 1 (PPV0) & $16.81 \pm 7.3$ & $10.23 \pm 4.86$ & $<0.001^{*}$ \\
\hline CO base $1(\mathrm{CO})(\mathrm{I} / \mathrm{m})$ & $4.5 \pm 0.21$ & $5.09 \pm 0.8$ & 0.220 \\
\hline PPV with TVC (PPV1) & $22.56 \pm 8.8$ & $12.27 \pm 5.88$ & $<0.001^{*}$ \\
\hline TVC PPV (delta PPV1) (PPV1-PPV0) & $5.75 \pm 2.35$ & $2.03 \pm 1.56$ & $<0.001^{*}$ \\
\hline CO with TVC (CO1) (I/m) & $3.93 \pm 1.25$ & $4.54 \pm 0.81$ & 0.055 \\
\hline PPV with PLR (PPV2) & $12.31 \pm 7.35$ & $8.07 \pm 3.9$ & $0.005^{*}$ \\
\hline PLR-PPV (delta PPV2) (PPV2-PPV0) & $4.5 \pm 1.55$ & $2.17 \pm 1.668$ & $<0.001^{*}$ \\
\hline $\mathrm{CO}$ with PLR $\left(\mathrm{CO}_{2}\right)(\mathrm{l} / \mathrm{m})$ & $5.23 \pm 1.08$ & $5.03 \pm 0.78$ & 0.720 \\
\hline PLR CO (delta $\left.\mathrm{CO}_{2}\right)\left(\mathrm{CO}_{2}-\mathrm{CO} 0\right)(\mathrm{I} / \mathrm{m})$ & $0.18 \pm 0.10$ & $-0.01 \pm 0.1$ & $<0.001^{*}$ \\
\hline CO base 2 (pre-VE) $(\mathrm{I} / \mathrm{m})$ & $4.58 \pm 1.16$ & $5.01 \pm 0.78$ & 0.308 \\
\hline PPV base 2 (pre-VE) & $15.06 \pm 6.87$ & $9.23 \pm 4.48$ & $<0.001^{*}$ \\
\hline PPV with VE (PPV3) & $8.13 \pm 1.75$ & $7.37 \pm 4.2$ & $0.024^{*}$ \\
\hline Delta PPV3 (PPV3-PPV pre-VE) & $6.94 \pm 5.94$ & $1.87 \pm 1.11$ & $<0.001^{*}$ \\
\hline $\mathrm{CO}$ with VE $\left(\mathrm{CO}_{3}\right)(\mathrm{l} / \mathrm{m})$ & $5.54 \pm 1.17$ & $5.08 \pm 0.8$ & 0.379 \\
\hline VE-CO (delta $\mathrm{CO}_{3}$ ) (CO with VE-CO pre-VE) & $0.22 \pm 0.07$ & $0.02 \pm 0.08$ & $<0.001^{*}$ \\
\hline
\end{tabular}

${ }^{*} p$-value statistically significant at <0.05; PPV: pulse pressure variation; CO: cardiac output; TVC: tidal volume challenge; PLR: passive leg raising; VE: volume expansion; SD: standard deviation

Table 4: Diagnostic ability of various variables to predict fluid responsiveness

\begin{tabular}{|c|c|c|c|c|c|c|c|}
\hline \multirow[b]{2}{*}{ Test result variable(s) } & \multirow[b]{2}{*}{ Area under the curve } & \multirow[b]{2}{*}{$p$ value } & \multicolumn{2}{|c|}{$95 \%$ confidence interval } & \multirow[b]{2}{*}{ Cutoff } & \multirow[b]{2}{*}{ Sensitivity (\%) } & \multirow[b]{2}{*}{ Specificity (\%) } \\
\hline & & & Lower bound & Upper bound & & & \\
\hline PPV (PPV0) & 0.870 & $<0.001^{*}$ & 0.766 & 0.974 & 10.5 & 87.5 & 83.3 \\
\hline TVC-PPV (delta PPV1) & 0.956 & $<0.001^{*}$ & 0.895 & 1.000 & 3.5 & 93.8 & 93.9 \\
\hline PLR-PPV (delta PPV2) & 0.877 & $<0.001^{*}$ & 0.772 & 0.982 & 2.5 & 87.5 & 80 \\
\hline VE-PPV (delta PPV3) & 0.894 & $<0.001^{*}$ & 0.801 & 0.986 & 2.5 & 81.3 & 83.3 \\
\hline PLR-CO (delta $\mathrm{CO}_{2}$ ) & 0.946 & $<0.001^{*}$ & 0.887 & 1.000 & 0.0659 & 93.8 & 86.7 \\
\hline
\end{tabular}

PPV0: (pulse pressure variation at baseline $6 \mathrm{ml} / \mathrm{kg} / \mathrm{lBW}$ ); delta PPV1: (PPV with tidal volume challenge test-PPV 0); delta PPV2: (PPV with PLR-PPV0); delta PPV3: (PPV with VE-PPV pre-VE); delta $\mathrm{CO}_{2}$ : (cardiac output with PLR-CO at baseline $6 \mathrm{~m} / \mathrm{kg}$ IBW)

in responders with sensitivity of $81 \%$ and specificity of $83 \%$ with area under the curve of 0.89 and best cutoff value of 2.5 (Table 4).

PPV and CO changes with tidal volume challenge, PLR and VE are shown in Table 4. PPV, PPV-TVC, PPV-PLR, CO-PLR, and PPV-VE tests showed statistically significant ( $p$-value $\leq 0.05$ ) between $R$ and NR as shown in Table 3, which means that they can be used for the discrimination of FR in hemodynamically unstable patients; however, the area under the curve was the highest for PPV-TVC (delta PPV1) 0.95 and CO-PLR (delta CO2) 0.94.

\section{Discussion}

Our study demonstrates that FR in hemodynamically unstable patients who are mechanically ventilated using low tidal volume can be efficiently predicted when PPV increases for more than 3.5 with tidal volume challenge and when PLR induces $6.5 \%$ increase in CO monitored through VTI method by Doppler echocardiography. And both tests are equally reliable with a comparable AUC.

In our study, responders had a significant increase in PPV with tidal volume challenge from 6 to $8 \mathrm{ml} / \mathrm{kg}$ IBW (delta PPV1) with best cutoff value of 3.5 with area under the curve of 0.95 with a sensitivity of $93.8 \%$ and a specificity of $93.9 \%$. Myatra et al. found that PPV with TVC strongly predicted FR with AUROC of 0.99 with a cutoff value of $3.5 ;^{11}$ the difference in specificity may be because we had relatively larger number of cases.

In agreement with our study, some studies have confirmed the reliability of delta PPV with tidal volume challenge 8 to $12 \mathrm{ml} / \mathrm{kg}$ for the detection of FR in patients with gray zone PPV (9-13) in perioperative settings and when VT was increased from 6 to $10 \mathrm{ml} / \mathrm{kg}$ PBW in critically ill patients. ${ }^{22,23}$ Also in operating room, PPV changes with TVC from 6 to $8 \mathrm{ml} / \mathrm{kg} / \mathrm{PBW}$ have reliably predicted $F R$ in neurosurgical patients and also during robotassisted laparoscopic surgery in the Trendelenburg position with lung-protective ventilation. ${ }^{24,25}$ The reason behind improved reliability of PPV with tidal volume challenge is that low tidal volume might be insufficient to make a considerable change in the intrathoracic pressure. ${ }^{26}$

PPV can be unreliable in ARDS patients as the transmission of airway pressure is reduced with a lower intrathoracic pressure changes in these patients due to low lung compliance $\left(C_{\text {stat }}\right) \cdot{ }^{26} \mathrm{PPV}$ reliability is reduced when static lung compliance $\left(C_{\text {stat }}\right)$ is less than $30 \mathrm{ml} / \mathrm{cm} \mathrm{H}_{2} \mathrm{O}{ }^{23,26}$ In our study, $\mathrm{C}_{\text {stat }}$ had increased to greater than $30 \mathrm{ml} / \mathrm{cm} \mathrm{H}_{2} \mathrm{O}(32.76 \pm 6.56)$ after the "tidal volume challenge."

We found that PPV at $6 \mathrm{ml} / \mathrm{kg}$ IBW tidal volume predicted FR with sensitivity of $87 \%$ and specificity of $83 \%$ with cutoff value of 10.5. Myatra et al. found that PPV at low tidal volume of $6 \mathrm{ml} /$ kg PBW did not predict fluid responsiveness with AUROC of 0.69 . 
This difference may be explained by our greater mean of PPV $16.81 \pm 7.3$ compared to $8 \pm 3$, which is nearly double their patient's number. ${ }^{11}$ We did not limit our study to patients in gray zone of PPV (10-13) to detect the actual sensitivity and specificity of each test in hemodynamically unstable patients. Even though PPV alone showed good reliability in our group of patients, reliability has increased with TVC. The $\triangle$ PPV with fluid challenge also reliably discriminated FR with sensitivity and specificity of $93 \%$ and $86 \%$, respectively; however, Myatra et al. reported 94\% sensitivity and $100 \%$ specificity with 0.98 AUC. $^{11}$

In our study, PLR test-induced changes in CO detected by echo VTI method predicted FR with a sensitivity of $93.9 \%$ and specificity of $86.7 \%$ with statistically best cutoff value of $6.5 \%$ increase in CO, with a less practical clinical significance, as it is difficult to detect such changes in CO using echocardiography VTI method and may be time-consuming, also when considering cutoff value of $10 \%$ increase in CO; sensitivity decreased to $75 \%$. Thiel et al. reported that SV rises by $15 \%$ or more during PLR predicted FR with a sensitivity and specificity of $81 \%$ and $93 \%$, respectively. ${ }^{15}$ Although direct CO measurement with thermodilution methods is reliable and easier than echocardiography, it is not always available.

In our study, we had a significant decrease in PPV with PLR (delta PPV2) in responders with $87.5 \%$ sensitivity and $80 \%$ specificity (best cutoff value 2.5 at AUC of 0.877 ). These data are consistent with Lamia et al. study which demonstrated that cardiac output changes or its directly derived parameters such as SV had a higher diagnostic significance than pulse pressure (PP) changes with PLR. ${ }^{17}$ Also during sepsis, pulse pressure is poorly correlated with stroke volume because of high total arterial compliance. ${ }^{27,28}$

\section{Strengths of the Study}

Ventilating patients on low tidal volume is a common practice today, and many of these patients share eligibility for PLR test and TVC-PPV. This is probably the first study with a direct comparison between these two common and reliable tests.

\section{Study Limitations}

PPV is unreliable in patients with cardiac arrhythmias or spontaneous breathing, and the use of tidal volume challenge cannot bypass these limitations. Echocardiography cannot be done in patients with poor window and does not give a direct measure of $\mathrm{CO}$ and needs some experience. Also, patients with PPV in a gray zone (9-13) need further study to confirm our findings.

\section{Conclusion}

Fluid responsiveness in hemodynamically unstable patients ventilated with low tidal volume strategy can be efficiently predicted when PPV increases more than 3.5 with tidal volume challenge and when PLR induces 6.5\% increase in CO monitored through VTI method by Doppler echocardiography, and both tests are equally reliable. Being simple, easily interpreted, and does not need CO monitoring, we recommend the use of TVC-induced changes in PPV.

\section{Acknowledgments}

The research team especially thanks each and everyone in the critical care department at Kasralainy hospitals for their utmost help and welcome that was priceless for the completion of the practical part of this research.

\section{ORCID}

Ahmed I Elsayed 나 https://orcid.org/0000-0001-7495-3494 Khaled AW Selim @ https://orcid.org/0000-0003-3679-3586

Hanan E Zaghla @ \. https://orcid.org/0000-0001-8840-498X

Hossam E Mowafy (0) https://orcid.org/0000-0003-3333-0754

Mohammed A Fakher @ https://orcid.org/0000-0002-7200-0806

\section{References}

1. Micek ST, McEvoy C, McKenzie M, Hampton N, Doherty JA, Kollef MH. Fluid balance and cardiac function in septic shock as predictors of hospital mortality. Crit Care 2013;17(5):R246. DOI: 10.1186/cc13072.

2. Messmer AS, Zingg C, Müller M, Gerber JL, Schefold JC, Pfortmueller CA. Fluid overload and mortality in adult critical care patients-a systematic review and meta-analysis of observational studies. Crit Care Med 2020;48(12):1862-1870. DOI: 10.1097/CCM.0000000000004617.

3. Jozwiak M, Silva S, Persichini R, Anguel N, Osman D, Richard C, et al. Extravascular lung water is an independent prognostic factor in patients with acute respiratory distress syndrome. Crit Care Med 2013;41(2):472-480. DOI: 10.1097/CCM.0b013e31826ab377.

4. Boyd JH, Forbes J, Nakada T, Walley KR, Russell JA. Fluid resuscitation in septic shock: a positive fluid balance and elevated central venous pressure are associated with increased mortality. Crit Care Med 2011;39(2):259-265. DOI: 10.1097/CCM.0b013e3181feeb15.

5. Michard F, Teboul J-L. Predicting fluid responsiveness in ICU patients: a critical analysis of the evidence. Chest 2002;121(6):2000-2008. DOI: 10.1378/chest.121.6.2000.

6. Marik PE, Cavallazzi R, Vasu T, Hirani A. Dynamic changes in arterial waveform derived variables and fluid responsiveness in mechanically ventilated patients: a systematic review of the literature. Crit Care Med 2009;37(9):2642-2647. DOI: 10.1097/CCM.0b013e3181a590da.

7. Marik PE, Cavallazzi R. Does the central venous pressure predict fluid responsiveness? An updated meta-analysis and a plea for some common sense. Crit Care Med 2013;41(7):1774-1781. DOI: 10.1097/ CCM.0b013e31828a25fd.

8. Monnet X, Marik PE, Teboul JL. Prediction of fluid responsiveness: an update. Ann Intensive Care 2016;6(1):1-11.

9. Hasanin A. Fluid responsiveness in acute circulatory failure. J Intensive Care 2015;3(1):50. DOI: 10.1186/s40560-015-0117-0.

10. De Backer D, Heenen S, Piagnerelli $M$, Koch M, Vincent J-L. Pulse pressure variations to predict fluid responsiveness: influence of tidal volume. Intensive Care Med 2005;31(4):517-523. DOI: 10.1007/s00134-005-2586-4.

11. Myatra SN, Monnet X, Teboul JL. Use of 'tidal volume challenge' to improve the reliability of pulse pressure variation. Crit Care 2017;21(1):60. DOI: 10.1186/s13054-017-1637-x.

12. Alvarado-Sánchez JI. The passive leg raising test (PLR). Colomb J Anesthesiol 2015;43(3):214-218. DOI: 10.1016/j.rcae.2015.03.005.

13. Cherpanath TGV, Hirsch A, Geerts BF, Lagrand WK, Leeflang MM, Schultz MJ, et al. Predicting fluid responsiveness by passive leg raising: a systematic review and meta-analysis of 23 clinical trials. Crit Care Med 2016;44(5):981-991. DOI: 10.1097/CCM.0000000000001556.

14. Monnet X, Marik P, Teboul J-L. Passive leg raising for predicting fluid responsiveness: a systematic review and meta-analysis. Intensive Care Med 2016;42(12):1935-1947. DOI: 10.1007/s00134-015-4134-1.

15. Thiel SW, Kollef MH, Isakow W. Non-invasive stroke volume measurement and passive leg raising predict volume responsiveness in medical ICU patients: an observational cohort study. Crit Care 2009;13(4):R111. DOI: 10.1186/cc7955.

16. Lafanechère $A$, Pène $F$, Goulenok $C$, Delahaye $A$, Mallet $V$, Choukroun $G$, et al. Changes in aortic blood flow induced by passive leg raising predict fluid responsiveness in critically ill patients. Crit Care 2006;10(5):1-8. DOI: 10.1186/cc5044.

17. Lamia B, Ochagavia A, Monnet X, Chemla D, Richard C, Teboul J-L. Echocardiographic prediction of volume responsiveness in critically ill patients with spontaneously breathing activity. Intensive Care Med 2007;33(7):1125-1132. DOI: 10.1007/s00134-007-0646-7. 
18. Vincent J-L and De Backer D. Circulatory shock. N Engl J Med 2013;369(18):1726-1734. DOI: 10.1056/NEJMra1208943.

19. Tan C, Rubenson D, Srivastava A, Mohan R, Smith MR, Billick K, et al. Left ventricular outflow tract velocity time integral outperforms ejection fraction and Doppler-derived cardiac output for predicting outcomes in a select advanced heart failure cohort. Cardiovasc Ultrasound 2017;15(1):18. DOI: 10.1186/s12947-017-0109-4.

20. MacFarland, Thomas W., and Jan M. Yates. "Mann-whitney u test." Introduction to nonparametric statistics for the biological sciences using R. Springer, Cham, 2016. 103-132. DOI: https://doi. org/10.1007/978-3-319-30634-6

21. Bewick V, Cheek L, Ball J. Statistics review 8: Qualitativedata - tests of association. Crit Care 2004;8:46-53. DOI: http://dx.doi.org/10.1186/ cc2428.

22. Min JJ, Gil NS, Lee JH, Ryu DK, Kim CS, Lee SM. Predictor of fluid responsiveness in the 'grey zone': augmented pulse pressure variation through a temporary increase in tidal volume. $\mathrm{Br} J$ Anaesth 2017;119(1):50-56. DOI: 10.1093/bja/aex074.

23. Charron C, Fessenmeyer C, Cosson C, Mazoit J-X, Hebert J-L, Benhamou $D$, et al. The influence of tidal volume on the dynamic variables of fluid responsiveness in critically ill patients. Anesth Analg 2006;102(5):1511-1517. DOI: 10.1213/01.ane.0000209015.21418.f4.
24. Messina A, Montagnini C, Cammarota G, De Rosa S, Giuliani F, Muratore $L$, et al. Tidal volume challenge to predict fluid responsiveness in the operating room. Eur J Anaesthesiol 2019;36(8):583-591. DOI: 10.1097/ EJA.0000000000000998.

25. Jun, J-H, Chung RK, Baik HJ, Chung MH, Hyeon J-S, Lee Y-G, et al. The tidal volume challenge improves the reliability of dynamic preload indices during robot-assisted laparoscopic surgery in the Trendelenburg position with lung-protective ventilation. BMC Anesthesiol 2019;19(1):142.DOI: 10.1186/s12871-019-0807-6.

26. Teboul, J-L., and X. Monnet. "Meaning of pulse pressure variation during ARDS." Annual Update in Intensive Care and Emergency Medicine 2011. Springer, Berlin, Heidelberg, 2011. 322-331. Doi: https:// doi.org/10.1007/978-3-642-18081-1_29

27. García MIM. Effects of fluid administration on arterial load in septic shock patients. Intensive Care Med. 2015;41(7):1247-1255. DOI: 10.1007/s00134-015-3898-7.

28. Cherpanath TGV, Smeding L, Lagrand WK, Hirsch A, Schultz MJ, Groeneveld JAB. Pulse pressure variation does not reflect stroke volume variation in mechanically ventilated rats with lipopolysaccharide-induced pneumonia. Clin Exp Pharmacol Physiol 2014;41(1):98-104. DOI: 10.1111/1440-1681.12187. 